\title{
UC-NRLF
}

| ( 


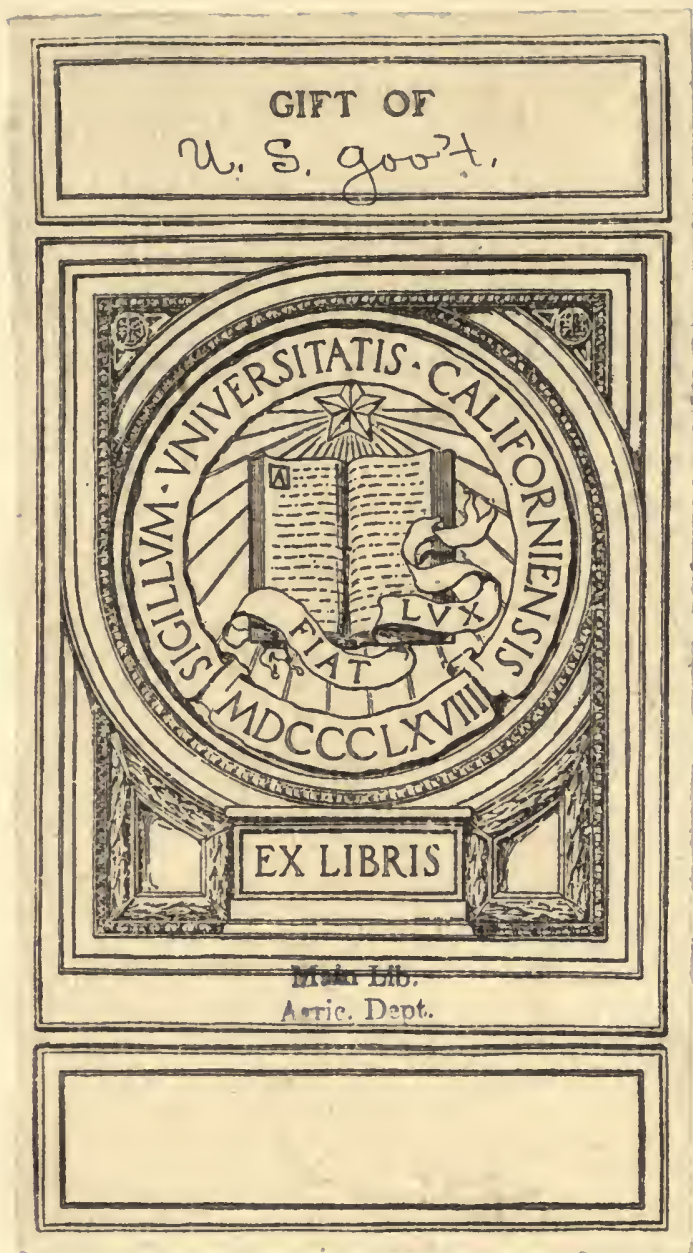



Digitized by the Internet Archive in 2007 with funding from Microsoft Corporation 



\title{
United States Department of Agriculturè,
}

\author{
BUREAU OF SOILS-CIRCULAR No. 70.
}

Muton Whitney, Chief of Bureau.

United States Department of Agriculture, Washington, D. C., May 21, 1912.

SIR: I have the honor to transmit herewith the manuscript of an article on Alunite as a Source of Potash, by W. H. Waggaman, Scientist in Fertilizer Resource Investigations, in this bureau, and to recommend that it be published as Circular 70 , of the Bureau of Soils.

Very respectfully,

Hon. JAMES Wilson, Secretary of Agriculture.

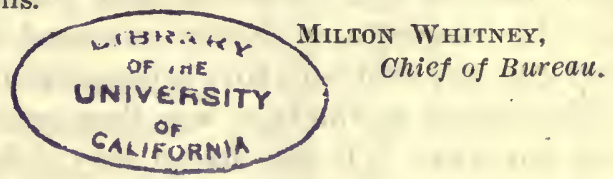

\section{ALUNITE AS A SOURCE OF POTASH.}

Alunite is a double sulphate of potassium and aluminum which, on heating, first gives off water and sulphur trioxide, leaving a residue

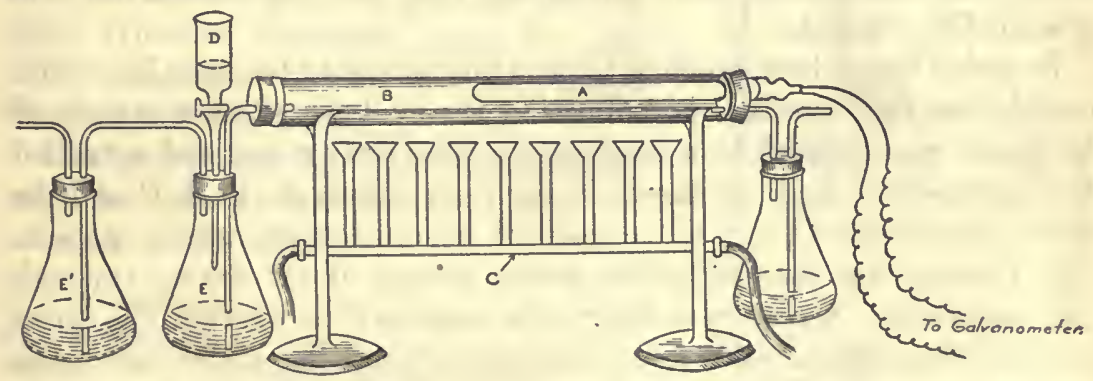

Fig. 1.-Apparatus for determining the temperature at which the decomposition of alunlte takes place.

consisting largely of potash alum. Upon increasing the temperature this latter compound decomposes with a further evolution of the oxides of sulphur, the final residue being chiefly potassium sulphate and alumina.

The alunite used in the experiments was a rather pure sample having the following analysis: 10.86 per cent $\mathrm{K}_{2} \mathrm{O}$ and 36.18 per cent $\mathrm{SO}_{3}$.

In order to determine the temperatures at which the decompositions took place the apparatus shown in figure 1 was constructed. 
- The pyrometer A was introduced into the tube $\mathrm{B}$ (preferably made of quartz) containing the sample of alunite and heated by the burners or furnace C. A solution of sodium carbonate was contained in the dropping funnel $\mathrm{D}$. The flask $\mathrm{E}$ containing water colored with a few drops of methyl orange was connected with an aspirator.

The burners were lighted and a gentle stream of air drawn through the apparatus, while the temperature, shown by the pyrometer, and the color of the methyl orange in the flask $\mathrm{E}$ were carefully watched.

At $520^{\circ} \mathrm{C}$. the oxides of sulphur began to come over and the color of the methyl orange changed to red. The acidity was neutralized by dropping in a little sodium carbonate from the funnel $\mathrm{D}$. At $530^{\circ} \mathrm{C}$. the evolution of gas became quite copious and the methyl orange again changed color. A drop or two of sodium carbonate was added and the temperature was kept at this point for 20 or 30 minutes. It was then increased to $670^{\circ} \mathrm{C}$., where the methyl orange again became red. Another drop of sodium carbonate was added and the temperature slowly increased to $750^{\circ} \mathrm{C}$. Apparently no more gas was evolved above a temperature of $700^{\circ} \mathrm{C}$.

The residue in the tube was then removed and washed repeatedly with hot water. It was found very difficult to wash the residue entirely free from soluble sulphates. At first sight this might be explained by hydrolysis of the aluminum sulphate and selective absorption of the alumina. The washings, however, gave no precipitate with ammonia or lime water, thus showing the absence of soluble aluminum compounds and indicating that the decomposition was practically complete.

In order to see how much sulphur trioxide could be actually recovered by heating alunite and collecting the evolved gases, a sample of 10 grams was ignited in a combustion tube drawn out and attached to an absorption train as shown in figure 2. Both the flask $B$ and the absorption bulbs $\mathrm{C}, \mathrm{C}^{\prime}, \mathrm{C}^{\prime \prime}$ contained a solution of caustic potash. The furnace was started and a gentle stream of air drawn through the apparatus. Great care had to be exercised to prevent the gases evolved from the alunite from passing through the entire train and escaping.

After heating the charge for a part of two days (eventually carrying the temperature to $700^{\circ} \mathrm{C}$.) the contents of the absorption train were emptied into a beaker, the bulbs and flask were carefully rinsed into the same beaker, the solution rendered slightly acid with hydrochloric acid, and made up to definite volume. Aliquots of this were then taken for analysis.

The temperature at which the final decomposition of the alunite takes place (viz, $700^{\circ} \mathrm{C}$.) is far above that at which sulphur trioxide is decomposed. Much of the gas evolved, therefore, was sulphur 
dioxide. Upon acidifying the potash solution a strong odor of sulphur dioxide was noticed. A little hydrogen peroxide and nitric acid were added, but considerable sulphur was lost which could have been saved by a suitable oxidizing agent.

In commercial practice platinized asbestos or some other catalytic substance could be introduced into the cooler end of the tube where the temperature is about $400^{\circ} \mathrm{C}$. The sulphur dioxide and oxygen passing over this would be again converted into the trioxide and thus saved. The absence of such impurities as arsenic and chlorine would obviate the necessity of washing the gases before passing them over the catalyzer.

The determination of sulphur trioxide in the alunite used in these experiments showed 26.88 per cent over and above that necessary to combine with the potash present. Theoretically this should all be evolved on ignition. The mean of two determinations, however, made as outlined above, gave an amount of sulphur trioxide recovered equal to only 23.05 per cent, showing a considerable loss as sulphur dioxide.

The ignited residue was then analyzed both for potash and sulphur. The results are given below:

$\mathrm{K}_{2} \mathrm{O}$ in residue

Per cent.

$\mathrm{SO}_{3}$ in residue 15.37

$\mathrm{SO}_{3}$ in residue over and above that com-

bined as $\mathrm{K}_{2} \mathrm{SO}_{4}$

1. 83

Alunite has been used heretofore for the manufacture of potash alum, ${ }^{1}$ either by heating to $400^{\circ}$ or $500^{\circ} \mathrm{C}$. and leaching out the alum thus produced, or by ignition at a higher temperature and subsequently treating the ignited residue with sulphuric acid and potassium sulphate.

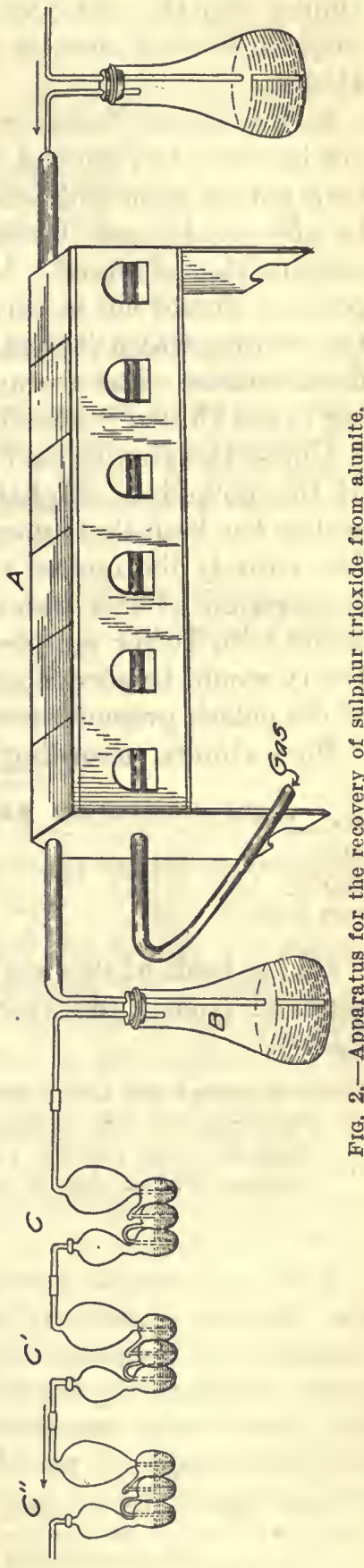

1 Guyot, M. P., Compt. Rend. Acad. Sci., Paris, 95, pp. 693-694, 1001-1003; Thorp, F. H., Outlines of Ind. Chem., pp. 259-260.

[Cir. 70] 
The production of potassium sulphate and alum by ignition of alunite and the collection of the evolved oxides of sulphur by absorption in some suitable medium are covered by French patent No. 419854.

In this patent, however, it is stated that the decomposition should not be carried to the end, but that the ignited residue should contain both potash alum and potassium sulphate, a separation of which can be afterwards made by lixiviating the residue and crystallizing the solution thus obtained. Although no reason is given why the decomposition should not be carried to an end, it is probably on account of the residue, which it is claimed after lixiviation is an excellent urtificial bauxite. The average price of natural bauxite in 1910, according to the United States Geological Survey, was $\$ 4.89$ per ton.

Unless the alunite used is very pure it is doubtful if the leaching of the potassium sulphate is economical. The experience of the author has been that an enormous volume of hot water is required to free entirely the ignited residue from soluble salts. The subsequent evaporation of this water is both tedious and expensive. Experiments with larger samples of alunite indicate that considerable idifficulty would be encountered in leaching. A recovery of 83 per cent of the potash present was obtained.

Pure alunite, according to Dana, has the following composition: ${ }^{1}$

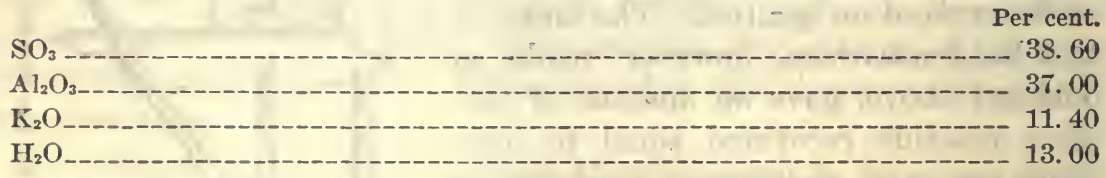

On the basis of this analysis the amount and value of the products obtained from 1 toin (2,000 pounds) of pure alunite, would be as follows: $=\geq \cdots$

Products from 1 toi (2,000 pounds) pure alunite:

Potash $\left(K_{2} \mathrm{O}\right), 220$ pounds, at 4 cents per pound $\$ 8.80$

Sulphuric acid $\left(52^{\circ} \mathrm{B}\right), 1,090$ pounds, at $\$ 6$ per ton

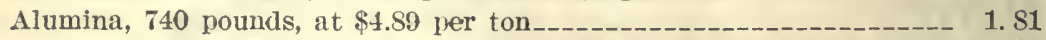

13. 88

From an economic standpoint it would seem more practical to use the ignited alunite (free from soluble aluminum compounds) directly as a fertilizer either alone or in mixed goods, since the expense of separating the soluble salts from the alumina would probably more than counterbalance the value of the alumina obtained. The percentage of potash in the ignited residue is considerably greater than in kainit, our chief source of soluble potash. 



RETURN TO the circulation desk of any University of California Library

$$
\text { or to the }
$$

NORTHERN REGIONAL LIBRARY FACILITY Bldg. 400, Richmond Field Station University of California Richmond, CA 94804-4698

ALL BOOKS MAY BE RECALLED AFTER 7 DAYS 2-month loans may be renewed by calling (510) 642-6753

1-year loans may be recharged by bringing books to NRLF

Renewals and recharges may be made 4 days prior to due date

\section{DUE AS STAMPED BELOW}

\section{MAR 211995}




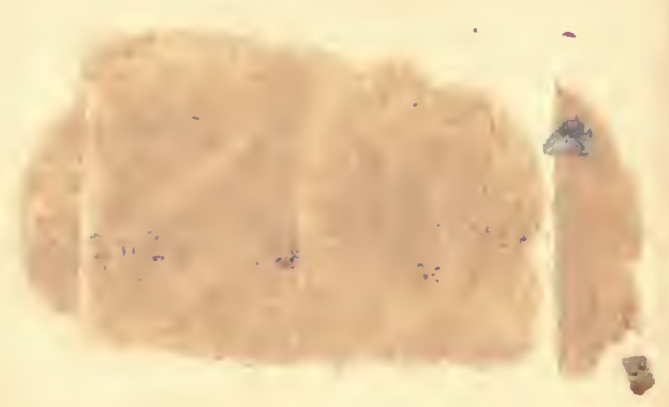

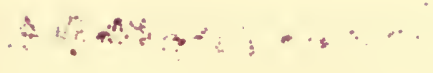


